\title{
Flame Heights and Heat Release Rates of 1991 Kuwait Oil Field Fires
}

\author{
DAVID D. EVANS, DANIEL MADRZYKOWSKI and GERALD A. HAYNES \\ Building and Fire Research Laboratory \\ National Institute of Standards and Technology \\ Technology Administration \\ U.S. Department Commerce \\ Gaithersburg, Maryland
}

\begin{abstract}
A series of measurements were made in the $\mathrm{Al}$ Mawqa/Al Ahmadi oil field region of Kuwait to explore the feasibility of assessing the heat release rate of individual well fires through flame height and thermal radiation measurements. The heat release rate ( $\dot{Q}$ in $\mathrm{kW}$ ) of the crude oil well fires was correlated with the flame height (Z, in meters) using $\dot{Q}=(\mathrm{Z} / 0.21)^{5 / 2}$. The 12 Kuwait oil field fires measured ranged in calculated heat release rate from $90 \mathrm{MW}$ to $2 \mathrm{GW}$ which correspond to flow rates of $0.003 \mathrm{~m}^{3} / \mathrm{s}$ ( $1500 \mathrm{bbls} /$ day) to $0.059 \mathrm{~m}^{3} / \mathrm{s}(30000 \mathrm{bbls} /$ day $)$. Based on these twelve burning well measurements, the estimated total flow from the 651 damaged wells, both burning and leaking in March, 1991, was $14 \mathrm{~m}^{3} / \mathrm{s}$ (7,400,000 bbls/day) which is only 20 percent greater than published National Oceanic and Atmospheric Administration (NOAA) estimates based on information from the Kuwait Oil Company.
\end{abstract}

KEYWORDS: Blowout Fires, Crude Oil, Flame Height, Flame Radiation, Jet Flames, Kuwait.

\section{INTRODUCTION}

As a result of the Iraqi invasion of Kuwait and the subsequent conflict 749 oil wells were systematically damaged with explosives in February 1991 resulting in uncontrolled gas 
and oil blowout fires of 610 wells[1] ${ }^{1}$. In November, 1991 the last burning oil well was extinguished and capped. The continuous generation of smoke and heat from these fires, during that nine month period, presented a potential environmental and health problem that was difficult to assess. This task was made even more difficult because many of the scientific centers in Kuwait were destroyed, and facilities stripped of scientific equipment that were necessary to perform measurements and predict future events.

As part of the international scientific response to the environmental and health emergency, the National Institute of Standards and Technology (NIST) in coordination with the United Nations Environment Programme (UNEP) performed preliminary and exploratory measurements to demonstrate the feasibility of determining the heat release rate of burning wells as an essential part of the characterization of the fires. These measurements satisfied one phase of the World Meteorological Organization (WMO) action plan [2] for assessment and monitoring of the air quality in the Kuwait region and its possible effects on human health. Details of the U.S. Government activities in the measurement and assessment of the environmental and health effects and impacts of the Kuwait oil field fires are contained in the Report to Congress, United States Gulf Environmental Technical Assistance [1].

\section{MEASUREMENTS}

Limited logistics support and time available for this exploratory study required the measurement equipment used to be light weight, portable, and robust. Based on previous research $[3,4]$, there were two means to estimate the heat release rate (HRR) of the fires; 1) based on the radiant heat flux that is emitted from the flame and 2) based on the flame height.

A Schmidt-Boelter thermopile type radiant heat flux sensor was used for the thermal radiation measurements. The sensor was covered by a sapphire window, which transmits $85 \%$ of the thermal radiation range from 0.15 micrometers to 5 micrometers, with a 90 degree view angle. The sensor was water cooled using a gravity fed system. The radiant heat flux measurement system had a useful range from $0.1 \mathrm{~kW} / \mathrm{m}^{2}$ to $10.7 \mathrm{~kW} / \mathrm{m}^{2}$. The voltage outputs were read and recorded manually from the display of a hand-held digital voltmeter. In the oil fields, measurements were taken at various distances from the fire where the thermal radiation could be measured without the use of special protective clothing. For the largest fires this was nominally $200 \mathrm{~m}$ from the burning well. Measurements were not corrected for atmospheric water absorption.

Both distances to the fires and the flame heights were measured using a surveying transit. Since close approach to the burning wells was impossible, the distance to well fires was determined using triangulation. The distance between two turning points at the ends of

1 Numbers in brackets refer to references at the end of this paper. 
a baseline (generally $100 \mathrm{~m}$ in length) was determined by tape measure. Then the angles from the baseline to the burning well were measured from the two ends of the baseline. From this information the distance between each end point of the baseline and the burning well was determined. The flame height was calculated from the measured elevation angle of the flame as seen from either end point of the baseline. In order to perform both surveying and flame height measurements, a commercial transit was modified by adding a low power scope which had a larger field of view than the high power transit scope. The larger field of view allowed more of the flame to be seen and facilitated the measurement of the flame height.

Using this equipment, five vertical-jet oil well fires were measured from the ground in the Al Mawqá and Al Ahmadi oil fields approximately $10 \mathrm{~km}$ south of Kuwait International Airport in Mid-May, 1991 (Figure 1). The continuous flame heights ranged from approximately $40 \mathrm{~m}$ to $70 \mathrm{~m}$ as shown in Table 1 . The continuous flame heights given in the table are averages of two measurements taken at each end of the baseline and rounded to the nearest $5 \mathrm{~m}$ increment. The reported continuous flame height was taken as the mid point of the continuous flame height fluctuation. For example, oil well number 1 had a continuous flame height of $65 \mathrm{~m} \pm 5 \mathrm{~m}$.

TABLE 1. Oil Well Ground Based Survey

\begin{tabular}{||c|c|c|c|c||}
\hline $\begin{array}{c}\text { Oil Well } \\
\text { No. } \\
\text { [This } \\
\text { Report] }\end{array}$ & $\begin{array}{c}\text { Oil Well } \\
\text { No. } \\
\text { [Kuwait } \\
\text { Oil } \\
\text { Company] }\end{array}$ & $\begin{array}{c}\text { Flame } \\
\text { Height } \\
(\mathrm{m})\end{array}$ & $\begin{array}{c}\text { Heat } \\
\text { Release } \\
\text { Rate } \\
(\mathrm{GW})\end{array}$ & $\begin{array}{c}\text { Oil Flow } \\
\mathrm{m}^{3} / \mathrm{s} \\
(\mathrm{bbls} / \mathrm{day})\end{array}$ \\
\hline \hline 1 & $\begin{array}{c}\text { AH-7 } \\
\text { NES }\end{array}$ & 65 & 1.7 & $\begin{array}{c}0.050 \\
(25,500)\end{array}$ \\
\hline 2 & $\begin{array}{c}\text { AH-23 } \\
\text { NCSC }\end{array}$ & 70 & 2.0 & $\begin{array}{c}0.059 \\
(30,000)\end{array}$ \\
\hline 3 & $\begin{array}{c}\text { AH-12 } \\
\text { NCS }\end{array}$ & 40 & 0.5 & $\begin{array}{c}0.015 \\
(7,500)\end{array}$ \\
\hline 5 & $\begin{array}{c}\text { AH-82 } \\
\text { NBR }\end{array}$ & 50 & 0.9 & $\begin{array}{c}0.026 \\
(13,500)\end{array}$ \\
\hline 5 & $\begin{array}{c}\text { AH-4 } \\
\text { NGS }\end{array}$ & 40 & 0.5 & $\begin{array}{c}0.015 \\
(7,500)\end{array}$ \\
\hline
\end{tabular}


A photographic flame height survey was also made from a helicopter. The flame heights were determined by comparing the flames with an object of known height in the photographs. In each instance a $2.44 \mathrm{~m}$ high fence, surrounded each oil well and served as the object of known height. Seven vertical jet oil well fires were surveyed using that method in the $\mathrm{Al}$ Minagish oil field (Figure 1). The maximum flame heights ranged from $35 \mathrm{~m}$ to $50 \mathrm{~m}$ in height. The measurements from this survey can be found in Table 2 .

TABLE 2. Oil Well Aerial Survey

\begin{tabular}{|c|c|c|c|}
\hline $\begin{array}{c}\text { Oil Well } \\
\text { No. }\end{array}$ & $\begin{array}{c}\text { Flame } \\
\text { Height } \\
(\mathrm{m})\end{array}$ & $\begin{array}{c}\text { Heat } \\
\text { Release } \\
\text { Rate } \\
(\mathrm{GW})\end{array}$ & $\begin{array}{c}\text { Oil Flow } \\
\mathrm{m}^{3} / \mathrm{s} \\
(\mathrm{bbls} / \mathrm{day})\end{array}$ \\
\hline \hline 6 & 45 & 0.7 & $\begin{array}{c}0.021 \\
(10,500)\end{array}$ \\
\hline 7 & 40 & 0.5 & $\begin{array}{c}0.015 \\
(7,500)\end{array}$ \\
\hline 8 & 35 & 0.4 & $\begin{array}{c}0.012 \\
(6,000)\end{array}$ \\
\hline 9 & 50 & 0.9 & $\begin{array}{c}0.026 \\
(13,500)\end{array}$ \\
\hline 10 & 20 & 0.09 & $\begin{array}{c}0.003 \\
(1,500)\end{array}$ \\
\hline 11 & 35 & 0.4 & $\begin{array}{c}0.012 \\
(6,000)\end{array}$ \\
\hline 12 & 40 & 0.5 & $\begin{array}{c}0.015 \\
(7,500)\end{array}$ \\
\hline \hline
\end{tabular}

Safety concerns over the possibility of unexploded ordnance in the region and time limitations allowed the radiant heat from only one of the five vertical-jet oil well fires to be measured. This oil well fire, Well \#1, was located at the intersection of two paved roads, was larger than most in the area, and did not have a crude oil pool fire around its base. Figure 2 is a photograph of this fire. The flame is seen to have a slight lean caused by morning winds (less than $5 \mathrm{~m} / \mathrm{s}$ ) blowing from left to right in the photograph. Measurements were made at $213 \mathrm{~m}, 193 \mathrm{~m}$, and $183 \mathrm{~m}$ radii from the fire. The radiant heat flux ranged from $1.4 \mathrm{~kW} / \mathrm{m}^{2}$ to $1.8 \mathrm{~kW} / \mathrm{m}^{2}$ at $213 \mathrm{~m}$ and $183 \mathrm{~m}$, respectively. 


\section{HEAT RELEASE RATE ANALYSIS}

Two methods of determining the HRR will be used in this analysis. The first method is based on the radiative heat flux measurement. The total heat release rate of a fire, $\dot{Q}$, is composed of two parts; a convective heat release rate fraction, $\dot{Q}_{c}$, and a radiative heat release rate fraction, $\dot{Q}_{r}$. Sivathanu and Gore [5] have shown in laboratory studies that ground level measurements of radiant heat flux from jet-flames measured with the radiometer pointed at $45^{\circ}$ from the ground plane at 2 to 3 flame lengths from the source can be used to estimate total radiative heat flux of jet-flames. As shown in figure 3 [5], measured radiant heat flux per unit area at a single ground position (R) radially 2 to 3 flame lengths from the source falls within 20 percent of the value representing the average flux over the spherical surface at that distance as defined by $\dot{Q} \chi_{r} /\left(4 \pi \mathrm{R}^{2}\right)$, where $\chi_{r}$ is the radiative fraction of the total heat release rate. Using the measured radiant flux at ground level as an average value, the total radiant heat release rate is:

$$
\dot{Q}_{Y}=4 \pi R^{2} \dot{q}^{\prime \prime}
$$

where:

$$
\begin{aligned}
& \dot{Q}_{r}=\text { Radiant HRR }(\mathrm{kW}) \\
& R=\text { Distance from sensor to fire }(\mathrm{m}) \\
& \dot{q}^{\prime \prime}=\text { Radiant flux }\left(\mathrm{kW} / \mathrm{m}^{2}\right)
\end{aligned}
$$

The radiative fraction $\left(\chi_{r}\right)$ of the total heat release rate [3] is defined as:

$$
\chi_{r}=\frac{\dot{Q}_{r}}{\dot{\ell}}
$$

Normally in laboratory experiments, the total heat release rate or fuel flow rate is known and the radiative fraction is calculated from measurements of the thermal radiation from the flame. In the case of the Kuwait fires, the opposite was true. The total heat release rate of the fire was sought for the purpose of estimating the fuel flow, and the radiative fraction was assumed based on previous research in the laboratory. Studies on the radiant fraction of laboratory scale, hydrocarbon gas diffusion flame fires have shown a radiant fraction range from 0.18 to 0.52 depending on the fuel type [3,4]. Fuels burning with a high radiant fraction provide more luminous flames than fuels which burn with a lower radiant fraction. Since the oil well fires were observed to be optically thick and quite luminous and since the composition of the burning oil/gas mixture is unknown, a range of radiant fractions from 0.35 to 0.55 was taken for this analysis. Utilizing the heat flux measurements for Well \#1, nominal HRR rates of $2.2 \mathrm{GW}$ and $1.4 \mathrm{GW}$ were calculated using the radiative flux measurements and assumed radiant fraction values of 0.35 and 0.55 respectively. 
For both jet and buoyant diffusion flames correlations have been developed to relate the flame height to the rate of heat release. Thus measurement of flame height may be a second and independent means of estimating the fire heat release rate. The heat release rate of oil/gas jet-fires has been correlated with flame height by Hustad and Sonju [6] using a modified Froude number analysis as:

$$
Z=C d F r_{m}^{0.2}
$$

where: $\quad \begin{aligned} & Z=\text { Flame height }(\mathrm{m}) \\ & C=\text { Fuel dependent constant } \\ & d=\text { Nozzle diameter }(\mathrm{m}) \\ & F r_{m}=\text { Modified Froude number. }\end{aligned}$

Assuming that the gas and oil are at the same velocity, $u$, the Froude number is modified to account for the gas stream's increased momentum due to the oil droplets presence in the gas jet.

$$
F Y_{m}=\frac{\left(1+\frac{\dot{m}_{o}}{\dot{m}_{g}}\right) u^{2}}{g d}
$$

where: $\quad \dot{m}_{o}=$ mass flow of oil $(\mathrm{kg} / \mathrm{s})$

$\dot{m}_{\mathrm{g}}=$ mass flow of gas $(\mathrm{kg} / \mathrm{s})$

$g \stackrel{g}{=}$ gravitational constant $\left(\mathrm{m} / \mathrm{s}^{2}\right)$

Unfortunately for analysis of the Kuwait oil field fires, the mass flow and in particular the ratio of the mass flow of oil to gas was unknown as was the mixture velocity at the well head.

A less than general means of assessing gas and crude oil well blowout jet-fires can be constructed from the meager amount of data available from laboratory experiments conducted by Dutta and Gore [7], Madrzykowski and Stroup [8], and the flame height and radiative heat release rate measurements made on a well fire in Kuwait. Figure 4 shows a direct dimensional plot of this experimental data for flame height vs. heat release rate. The data from Dutta and Gore [7] were measured using an effervescent atomizer burner with a $5 \mathrm{~mm}$ effective outlet diameter. The data represents mixtures of crude oil and methane with liquid crude oil mass fractions of 80 to 95 percent. Madrzykowski and Stroup [8] measured crude oil and methane jet-flame with a crude oil mass fraction of 50 percent and an outlet diameter of $50 \mathrm{~mm}$. This fire had a calculated heat release rate based on complete combustion of the fuel of $18.5 \mathrm{MW}$ and a flame height of 11 meters. The average heat release rate determined from radiation 
measurements for the Kuwait Well \#1 of $1.7 \mathrm{GW}$ and measured flame height of $65 \mathrm{~m}$ were used for the plot in figure 4.

The data indicates a $5 / 2$ power variation of flame height with heat release rate. In fact, the dotted line shows that the data, which span five orders of magnitude in heat release rate, are correlated by an expression originally developed by Hasemi and Tokunga [4] for buoyancy dominated turbulent gas burner flames of approximately $100 \mathrm{~kW}$ of the form:

$$
\dot{Q}=\left(\frac{Z}{0.21}\right)^{5 / 2}
$$

$$
\text { where: } \quad \dot{Q}=\operatorname{HRR}(\mathrm{kW})
$$

The agreement between the two seemingly unrelated cases is very good. This indicates that even though the jet-flames have substantial initial momentum, for the high liquid fraction of these fires, the flames contain substantial buoyancy effects as well. Further experiments are needed to examine if this correlation can be generalized to other high initial momentum liquid fuel jet-flames.

For the present, the correlation will be used to assess the HRR of other fires from flame heights that were photographed in the Kuwait oil fields. The HRR for the other 11 well fires was calculated using the measured flame height and equation (5) with results listed in Table 2.

The objective of this field study was to assess the fuel flow rate from the wells. To do this the fuel flow of each well that was measured, in this study, was estimated by dividing the calculated HRRs by a nominal heat of combustion for crude oil, $42600 \mathrm{~kJ} / \mathrm{kg}$ [9]. As an example, for the $1.7 \mathrm{GW}$ Well \#1 fire, this procedure yields a fuel mass flow of $40 \mathrm{~kg} / \mathrm{s}$. Using a fuel density of $800 \mathrm{~kg} / \mathrm{m}^{3}$ the corresponding volumetric fuel flow would be $0.05 \mathrm{~m}^{3} / \mathrm{s}$ ( $25000 \mathrm{bbls} /$ day). These estimates are assuming no energy contribution from the gas.

The average oil flow given by the twelve oil wells listed in Tables 1 and 2 is $0.022 \mathrm{~m}^{3} / \mathrm{s}$ (11,375 bbls/day). The National Oceanic and Atmospheric Administration (NOAA) [10] estimated that in mid-March of 1991 there 651 wells burning and leaking $11.7 \mathrm{~m}^{3} / \mathrm{s}$ (6,186,000 bbls/day) of oil. Multiplying the average flow of the twelve listed wells by 651 yields a total oil flow of $14 \mathrm{~m}^{3} / \mathrm{s}(7,400,000 \mathrm{bbls} / \mathrm{day})$, which is 20 percent greater than the NOAA estimate.

\section{CONCLUSIONS}

Analysis of the measurements and samples taken in the $\mathrm{Al}$ Mawqá/Al Ahmadi oil field region demonstrated the feasibility of using near field, ground based measurements to 
determine the fire source intensity. This exploratory study demonstrates that characterizing a large fire is possible and would provide good source term data for use in the meteorology and health effects models. Extrapolating the measurements made on 12 wells to the entire 651 damaged wells results in an estimated $14 \mathrm{~m}^{3} / \mathrm{s}$ $(7,400,000 \mathrm{bbls} / \mathrm{day})$ of oil leaking and burning from damaged wells in Kuwait.

\section{ACKNOWLEDGEMENTS}

Appreciation is extended Mr. Ceasar Santucci and Mr. Eunice Ford of the Army Corps of Engineers and to the 986th Medical Detachment, Virginia Army National Guard for their logistical support. Professor Jay Gore of Purdue University provided means to analyze the data from this study using results from his laboratory experiments. James Brown measured the $\mathrm{CO}_{2}$ concentration in the bag samples and Randall Lawson assisted in the preparation of the smoke particulate and gas sampling equipment. A special thanks goes to Lauren DeLauter, Jay McElroy, Roy McLane, Gary Roadarmel, Bob Vettori, Henry Wheelock and Richard Zile for their assistance in procuring, fabricating and calibrating the equipment needed for this project.

\section{REFERENCES}

1. U.S. Environmental Protection Agency, Report to Congress, United States Gulf Environmental Technical Assistance from January 27 - July 31, 1991 Under Public Law 102-27, Section 309, October, 1991.

2. Report of the World Meteorological Organization Meeting of Experts on the Atmospheric Part of the Joint U.N. Response to the Kuwait Oilfield Fires, Geneva, 27-30 April 1991.

3. McCaffrey, B.J., Some Measurements of the Radiative Power Output of Diffusion Flames, WSS Combustion Meeting, Paper No. WSS/CI 81-15, Pullman (1981).

4. Hasemi, Y., Tokunga, T., Modeling of Diffusion Flames and Fire Plumes for the Analysis of Fire Growth, Fire Dynamics and Heat Transfer, The American Society of Mechanical Engineers, 21st National Heat Transfer Conference, HTD-Vol. 25, (1983).

5. Sivathanu, Y.R., Gore, J.P., Total Radiative Heat Loss in Jet Flames from Single Point Radiative Flux Measurements, Combustion and Flame , 94: 265-270, (1993).

6. Hustad, H., Sonju, O.K., Radiation and Size Scaling of Large Gas and Gas/Oil Diffusion Flames. Dynamics of Reactive Systems Part I: Flames and Configurations, Vol 105 of Progress in Astronautics and Aeronautics series. Published in 1986 by the American Institute of Aeronautics and Astronautics N.Y. 
7. Dutta, P. and Gore, J.P., "Flame Height and Radiation Properties of High Liquid Loading Two Phase Spray Fires," 1993 Annual Conference on Fire Research: Book of Abstracts, NISTIR 5280, Wanda J. Duffin, Editor, National Institute of Standards and Technology, Gaithersburg, MD, pp167-168, October, 1993.

8. Madrzykowski, D., Stroup, D. W., Radiation Reduction of Jet Flames by External Water Injection, to be published.

9. Babrauskas, V, "Burning Rates,"SFPE Handbook of Fire Prot. Engr., Sec. 2, Ch. 1, 1988.

10. Kuwait Oil Extinguishing Chronology, Gulf Program Office, Office of the Chief Scientist, National Oceanic and Atmospheric Administration, November 1991.

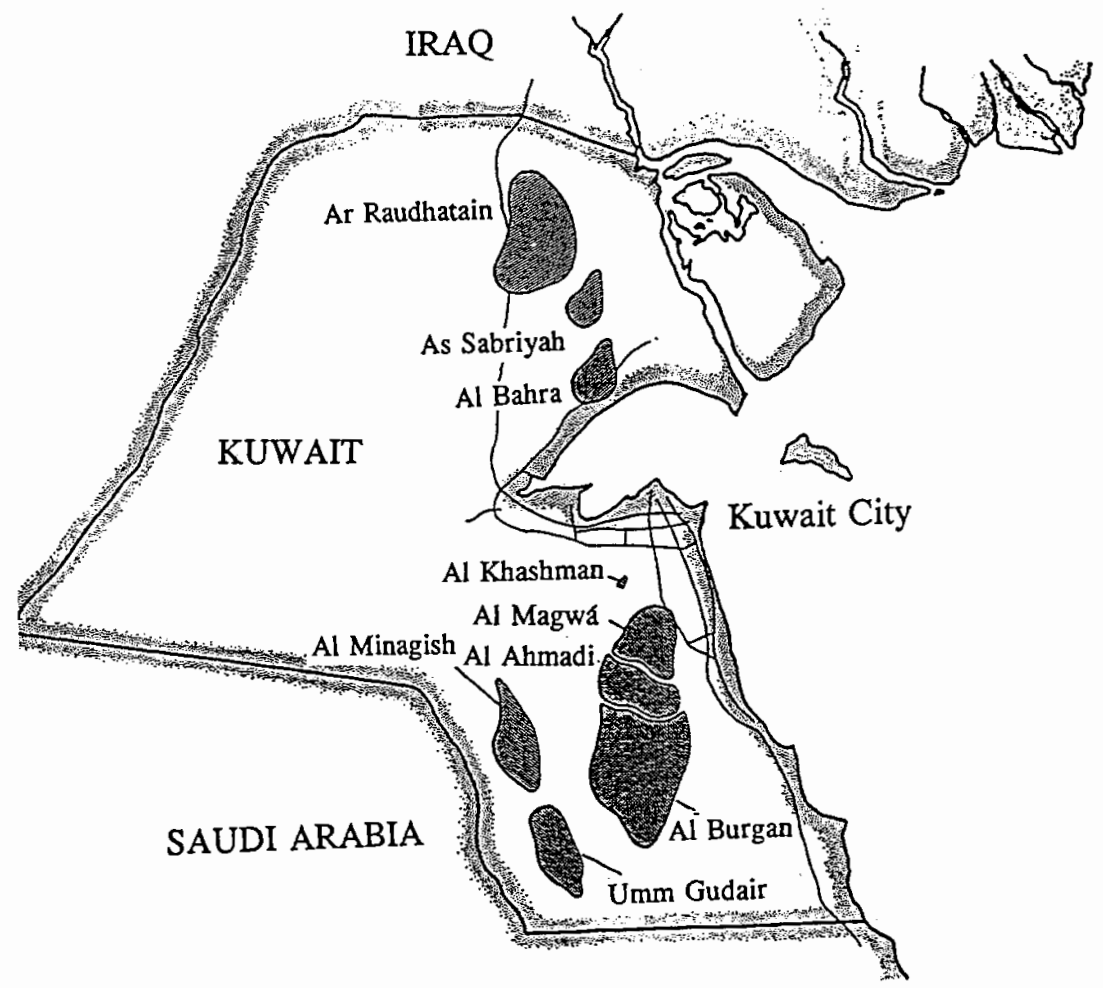

FIGURE 1. Map Kuwait Showing the Locations of the Al Maqwá, Al Ahmadi, and Al Minagish Oil Fields. 


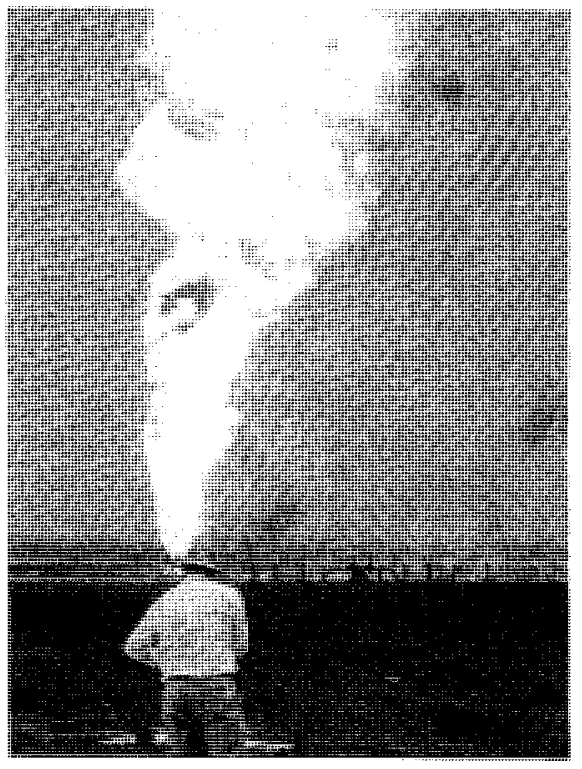

FIGURE 2. Measurement of flame height at AH-7 NES (Well \#1) in Kuwait.

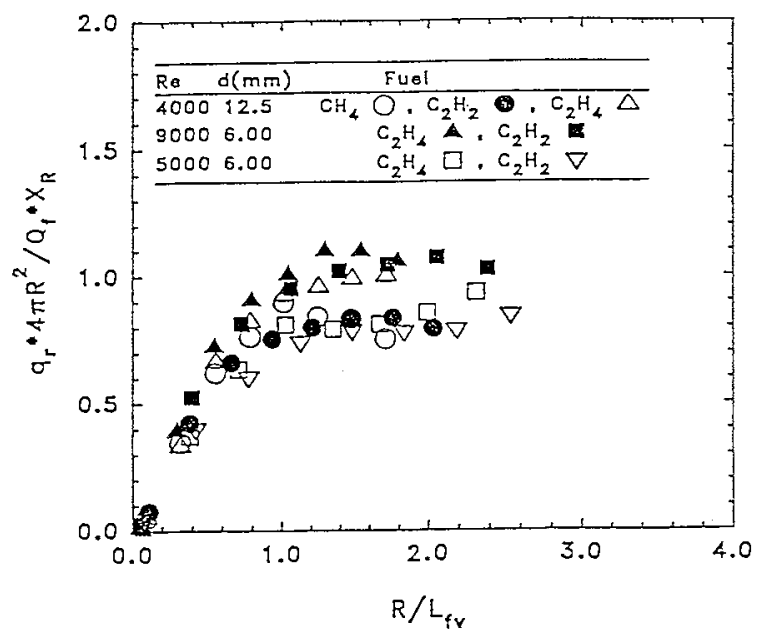

FIGURE 3. Ratio of total radiative flux based on single point ground level measurements to that based on radiative fraction for various jet flames, ( $\mathrm{L}_{\mathrm{f}}$ is the flame length) [5]. 


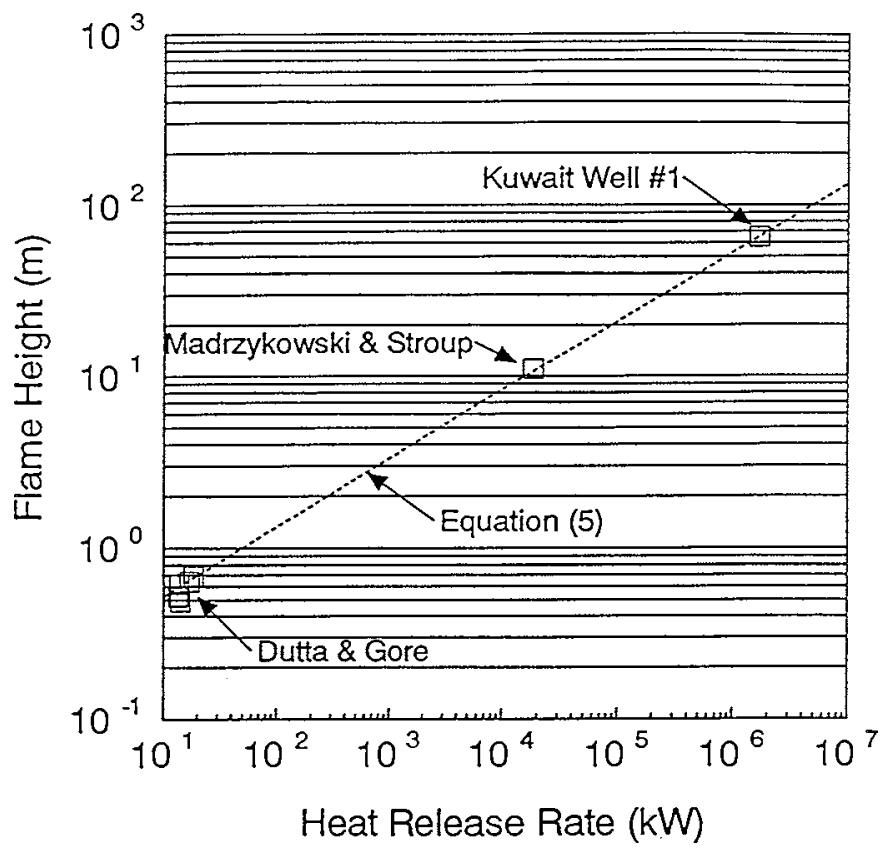

FIGURE 4. Heat Release Rate vs. Flame Height. 
